\title{
The Construction of the Inheritance System of Traditional Music in Liangshan Prefecture in the Context of Intangible Cultural Heritage
}

\author{
Ling Chen ${ }^{1, *}$ \\ ${ }^{1}$ Institute of Taoism and Religious Culture, Sichuan University, Chengdu, Sichuan, China \\ *Corresponding author. Email: scucl2020@163.com
}

\begin{abstract}
The inheritance system of traditional music in Liangshan Prefecture is a whole composed of multiple factors and multiple links. These factors influence and restrict each other. To build a complete music inheritance system and run it efficiently, it is necessary to integrate all links and give full play to all factors in the link. Since 2008, a number of traditional music in Liangshan Prefecture has been selected as national intangible cultural heritage. Against the background, the key of constructing the inheritance system is to make the inheritance content and mode which depend on the inheritance site and basic requirements keep their national character and uniqueness in the process under the overall construction. This article aims to explore the factors in the inheritance process and constructs a set of inheritance system suitable for traditional music in Liangshan Prefecture. It can continue the vitality of traditional music in Liangshan Prefecture to a certain extent. More importantly, it can open up a new contemporary life space for traditional music and construct a comprehensive and overall view of living development.
\end{abstract}

\section{Keywords: intangible cultural heritage, Liangshan, traditional music, system construction}

\section{INTRODUCTION}

Liangshan refers to Liangshan Autonomous Prefecture of Yi Nationality. Although there is "Yi nationality" in the name, it does not mean that there is only Yi nationality in Liangshan Prefecture. There are other ethnic groups, such as "Tibetan nationality, Qiang nationality and so on in Liangshan Prefecture. Therefore, when referring to the traditional music culture of Liangshan Prefecture, this paper not only discusses the unique music culture of Yi nationality, but also the music culture of Tibetan nationality, Qiang nationality and other nationalities. Since 2004, much traditional music in Liangshan Prefecture has been included in the protection list of national, state and provincial intangible cultural heritage, but most of the traditional music only relies on oral and heart-to-heart teaching, lacking a complete inheritance system. Nowadays, with the impact of multiculturalism and world integration, the traditional music is faced with a series of difficulties, such as on the verge of disappearing and passing down from generation to generation. Therefore, the construction of traditional music inheritance system is conducive to the inheritance of traditional music culture, the innovation and development; secondly, it will lay a solid foundation for the development of cultural industry in
Liangshan Prefecture. Therefore, people can see that the inheritance of the traditional music culture in the context of intangible cultural heritage is not only a matter for the state and the government, but also an important task for each of us.

In addition, it also needs to make the following definition of the protection of intangible cultural heritage mentioned in this paper. First of all, the protection of intangible cultural heritage is not only to make the excavation, protection and rescue of its works, but also includes the living protection and humane concern for the inheritors and their culture. Through the research of traditional music in Liangshan Prefecture, it is required to try the best to explore the most essential thing behind the music text culture, and inherit the spiritual and cultural connotation contained in these contents. This makes the inheritance way and content particular, breaking away from the solid symbols, tones, lyrics and influences that people are familiar with. When people look for the unique group living customs and the spiritual connotation in the Liangshan Prefecture, the living inheritance in the contemporary social and cultural environment can be realized. So what is the meaning of living inheritance? The author thinks that it should be the spiritual wealth that people in Liangshan Prefecture have generated in their life generation after generation, that is, generating from 
their history, culture, knowledge and identity. This is the most unique cultural memory, and also puts forward a great challenge for the construction of music inheritance system.

\section{ANALYSIS ON THE ELEMENTS OF INHERITANCE SYSTEM}

In fact, the inheritance system of traditional music is a very large system. If people want to inherit and develop it effectively, it is necessary to first find out several main factors that constitute the inheritance system. Generally speaking, it can be divided into five main factors: the disseminator, the successor, the inheritance site, the inheritance content and mode, and the basic requirements of inheritance mechanism and protection.

\section{A. Disseminators}

The disseminators here mainly refer to the inheritors and some performing artists of traditional music. The disseminator is the backbone of the whole inheritance system, and also the transmitter and disseminator of music culture. In this system, people can look at it from a vertical perspective. From the perspective of time, the general disseminators are teachers, parents, brothers and sisters, etc. However, in the process of its inheritance and development, it is necessary to pay attention to some horizontal spatial performance, such as the inherent relationship among adjacent villages, peer groups and friends, and so on. In modern society, the lateral significance of the disseminator is further expanded. For example, media, local government, amateur music organizations and so on have become the disseminators of traditional music culture.

\section{B. Successors}

The so-called successors are the receivers and inheritors of cultural heritage and the main body of music culture inheritance. The successors mainly refer to the inheritors and the young men and women who are interested in them. With the development of science and technology, the successors can be further expanded to the audiences that are exposed to music through mass media.

\section{Inheritance site}

The inheritance site is the place where the disseminators and the successors carry on the music culture inheritance activity. First of all, it is not limited to the specific material space, such as schools, villages, art museums, intangible cultural heritage museums, but also includes the more complex social and cultural spiritual space, such as the year of the Yi nationality, Torch Festival, Bimo ceremony, etc. Nowadays, with the development of the times, it can even be inherited in some short videos. These heritage sites include natural space, social and cultural space, as well as virtual space, which provide more development possibilities for the inheritance of intangible cultural heritage.

\section{Inheritance content and mode}

The inheritance content of this paper is not only to inherit its music form and content, but also to explore and trace the culture, national art, folk custom and life style. The inheritance way of traditional music in Liangshan Prefecture mainly refers to a folk oral and heart-to-heart way, including teachers and apprentices, families, villages, festivals and other ways; with the development of the times, the inheritance mode in the new era has changed into a variety of modes, mainly including media heritage ${ }^{1}$, school heritage, art venue inheritance, etc. The inheritance mode discussed in this paper is just the combination of folk inheritance and traditional inheritance in the new era.

\section{E. Basic requirements of inheritance mechanism and protection}

The study environment here mainly refers to the basic requirements of inheritance mechanism and protection. It guarantees the healthy development of traditional music culture inheritance from the aspects of system, law, government policy and some folk inheritance mechanism, including the operation mechanism of inheritance system and evaluation and control system, etc.

\section{EXPLORING THE OPERATION MECHANISM OF INHERITANCE SYSTEM}

The inheritance system of traditional music in Liangshan Prefecture is a very complex process. To make the whole system operate well, it is required to put these main factors in a situation of mutual influence and mutual restriction. First of all, the relationship between imparter and successor is opposite and unified. The disseminators transmit and output traditional music, while the successors receive and accept it, forming the binary relationship between the starting point and the end point of the whole inheritance system. However, it is necessary to pay attention to the fact that the roles of the disseminator and the successor can be mutually transformed. Although they are in a binary state, they are not antagonistic. The disseminator is also the inheritor who accepts the traditional music, and the inheritor can absorb and digest the content he has received, so as to become the disseminator of traditional culture.

As shown in "Fig. 1", the inheritance content and inheritance mode are the core of the whole system. On

\footnotetext{
1 The media inheritance here mainly refers to paper media and modern media such as newspapers, magazines, and the Internet in contemporary society.
} 
the one hand, they are the links between the disseminator and the successor. On the other hand, they are also limited by the inheritance site and basic requirements of inheritance mechanism and protection. As heritage content is different, inheritance site will have corresponding changes, and different inheritance content can be presented and developed in different inheritance sites. For example, the Bimo music of Yi nationality narrates the national story, tells the history, explores the origin of all things, and shapes (including ghosts and gods) characters in specific ritual activities by chanting and singing. The traditional music can only be inherited in the social relationship field composed of master and apprentice in specific occasions. In the whole system, the degree of preference for music, age, family environment and the choice of inheritance mode and strategy will also affect the content of music culture.

It can be seen that several factors in the system are indispensable. They restrict and influence each other. If any element is missing, the effect of its inheritance will be affected. Of course, Liangshan Prefecture has added a lot of security mechanisms to many traditional music of intangible cultural heritage, and the construction system of intangible cultural heritage project list has been basically sound, and the inheritance system is moving towards a benign direction. However, there are still some problems. It is necessary to make each factor in the inheritance system play its role, and effectively coordinate and integrate the factors in each link, so as to lay a solid foundation for the good operation of the entire inheritance system.

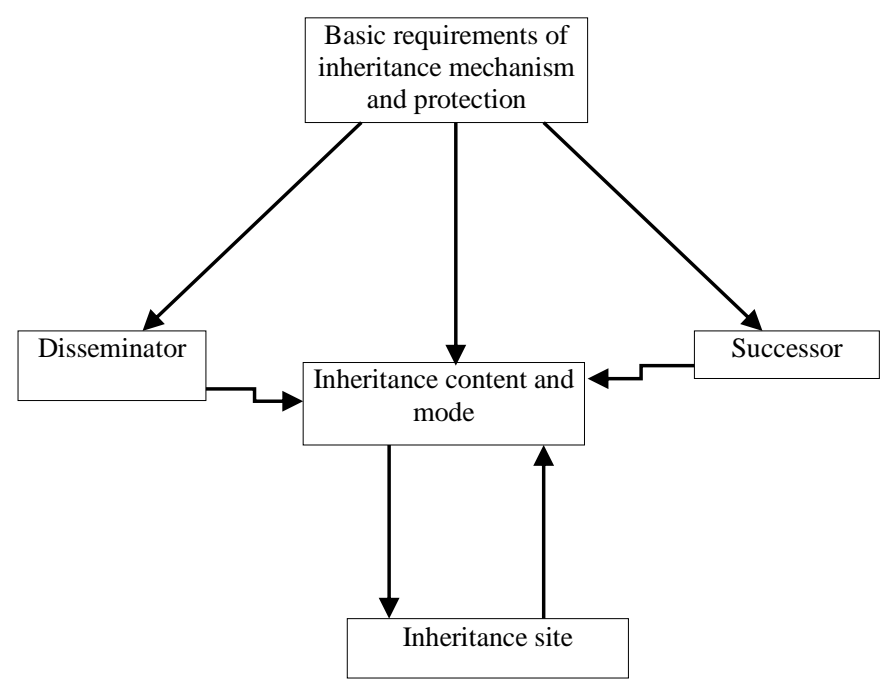

Fig. 1. Inheritance operation mechanism.

\section{CONSTRUCTION OF INHERITANCE SYSTEM OF TRADITIONAL MUSIC IN LIANGSHAN PREFECTURE IN THE CONTEXT OF INTANGIBLE CULTURAL HERITAGE}

\section{A. There is a close relationship between the disseminator and the successor}

The disseminator is not only the transmitter and communicator of music culture, but also the backbone of the whole inheritance system. They always carry the vivid collective consciousness and memory of the whole nation, and contain the thought and wisdom of the nation. Therefore, in order to inherit the traditional music culture of Liangshan Prefecture, it is necessary to protect its the inheritors. Looking at the current situation of inheritors, it is difficult for them to obtain some direct economic benefits by singing and making musical instruments. This realistic factor directly hinders their adherence to tradition and affects the survival of traditional music. In order to improve this situation, the government and relevant departments should promulgate relevant measures and systems to intervene. For example, the government can provide certain policy and fund support for some intangible cultural heritage projects of traditional music, so as to make music cultural resources gradually transform towards cultural capital. Secondly, it provides certain subsidies for the disseminators in the form of projects, so as to strengthen the responsibilities and obligations of the disseminators and ensure the promotion and development of music culture. In addition, the local government and relevant departments can also get in touch with the TV programs related to intangible cultural heritage, so that the disseminator of traditional music in Liangshan Prefecture can participate in many exhibitions and exchange activities in China and foreign countries, so as to enhance the confidence of the disseminators and protect the survival status of the inheritors. 
Up to now, there are 1372 intangible cultural heritage projects, but only 3068 inheritors $^{2}$ have been registered. Many intangible cultural heritage projects have only one inheritor, and some intangible cultural heritage projects are facing the situation of no successor. In such an environment, in addition to protecting them, it is more important to rescue them. Inheritors are the most basic characteristics of intangible cultural heritage, and intangible cultural heritage projects cannot survive without inheritors. In order to save the inheritors, it is necessary to solve the current problems. Recording the inheritors is also the fundamental measure to record, rescue, protect and continue the intangible cultural heritage. There are two kinds of records of inheritors: one is to record the inheritors' works and their skills; the other is to record their oral history and skill combined with works. Oral history and the inheritance of skills are the more important part. In recent years, various disciplines have emphasized the importance of oral history of various nationalities. First of all, oral history is different from the production of works, works and skills, which is the life history of inheritors, the experience and wisdom contained in their lives, the text analysis of themselves, and the life and lifeblood of local people.

In addition, successors are now affected by the multiculturalism. Many young people are not interested in the traditional music of their own nation and are not willing to study it. Or they are affected by the market economy to go out to work and do not pass on the national culture. On the other hand, from the perspective of successors, they generally have no interest in traditional music due to the impact of today's multiculturalism, so there is a weak state of their appreciation of traditional music. Therefore, it is necessary to guide the successors to appreciate more traditional music works, and gradually let them be influenced by the subtle influence, so as to have the inner drive and be interested in studying and learning these things. Successors are the most important audience in the whole inheritance system. Without successors, the whole system cannot work well. Therefore, it is necessary to create a good music atmosphere for successors. The successors and the disseminators are closely linked together, so that they can support the whole inheritance system.

\section{B. Expanding the inheritance ways}

Nowadays, the social environment has undergone earthshaking changes. Due to the fact that many traditional music inheritance methods in Liangshan area are one-to-one oral teaching, the inheritance mode is

This data comes from China Intangible Cultural Heritage Network - China Intangible Cultural Heritage Digital Museum "Representative Inheritors of Representative Projects of National Intangible Cultural Heritage" http://www.ihchina.cn/representative\#target 1 relatively narrow, which cannot meet the requirements of the new era, and has certain limitations in the face of the challenges posed by the new period. Different from Bimo music, the outstanding intangible cultural heritage music culture, such as Aguhe, Lire'er, Areniu, has no fixed inheritance pedigree. As long as people are interested in this kind of music, they can go to learn from their teachers. Due to the particularity of music culture, this traditional music inheritance mode is impossible to be replaced. People need to have a correct understanding of this music inheritance mode in all aspects, recognize its role in the inheritance, protect and construct the existing state of this folk traditional inheritance mode, and take certain measures to improve the tradition according to the development of science and technology, and combine it with modern inheritance.

In recent years, in order to innovate the protection methods of intangible cultural heritage, Liangshan Prefecture has carried out the measures of "intangible cultural heritage activities going into the campus and the countryside". To a certain extent, it alleviates the lack of inheritance of intangible cultural traditional music, but it is only a relatively fixed music project, which does not give full play to the role of school education in inheriting traditional music. And there is also a lack of systematicness, coherence and progressiveness for the inheritance of music. Students of different regions, ages and personalities have different interests in music, and their abilities to accept music are also different. Therefore, when formulating measures, it is necessary to select appropriate inheritance content and mode for different regions and different types of schools, and assign different inheritance objectives by region and school. It is required to conduct a continuous teaching for students of different age levels, carry out music education activities, improve the traditional music examination system, and appropriately bring it into the category of final examination. At the same time, it is better to formulate a series of policies, improve the measures of intangible cultural heritage going into the campus, and give full play to the inheritance role of contemporary schools. In addition, the government can also vigorously develop cultural industry and tourism. Through these intangible cultural heritage projects such as Torch Festival in Liangshan Prefecture, the local folk customs are publicized, and the successors are introduced into the music text, so that they can enjoy the music and immerse themselves in cultural activities. Only in this way can they enjoy the music from their hearts and study the music culture by themselves. This way of inheritance can effectively link the local economic construction, folk customs and music inheritance together.

Secondly, public cultural venues can be improved. The inheritance content in this inheritance mode is 
relatively extensive and refined. It can display a number of intangible cultural heritage projects at the same time, and successors can better accept it. However, at present, it has not fully played the role of this way of inheritance. In this regard, first of all, it is necessary to carefully select the inheritance content of public cultural venues, so that the intangible cultural heritage projects related to traditional music of Yi nationality in Liangshan Prefecture can get a certain theoretical supplement. And then, people can have an intuitive feeling and understanding of them, and classify these venues, and some of which are open to the audience free of charge. Second, the government can support and improve the construction of venues, such as increasing the number of cultural centers and building relevant public cultural facilities, and at the same time, encourage and stimulate the development and construction of folk art museums, provide certain financial subsidies for them, and promote the diversified development of public cultural venues. It is required to learn from the excellent venues construction in the west or other places, and cooperate with the society, schools and scientific research institutes to broaden the inheritance function and direction of these cultural venues.

In addition, with the continuous development of science and technology, a variety of digital technology and new media inheritance occupy most of the space of people's life. Young people also prefer to understand and learn music culture through new media and new technologies. Therefore, people can reasonably use and develop mobile app software, such as short video software and live broadcast software, to spread traditional music. Breaking the limitation of time and space, people can quickly pay attention to the local traditional music on the Internet anytime, anywhere. On the one hand, it can develop its music audience; on the other hand, it can innovate the inheritance mode and is no longer limited to the traditional way, catering to the development of the times. Then, it will open a new and contemporary life space for the development of traditional music in Liangshan Prefecture.

\section{Improving the inheritance mechanism and security system}

The security system mainly depends on the government's policies, laws and regulations as well as the strategies and measures for the whole system, which is a prerequisite for the good operation of the whole system. The government and relevant departments need to establish a correct concept of inheritance for the disseminators, inheritors and inheritance contents under the continuous study of the inheritance content. On this basis, the government should constantly improve the inheritance mechanism and security system, so as to achieve a complete inheritance route of understanding, deepening research, protection and development, innovation and inheritance. First of all, the government can improve the heritage protection law for the inheritors of intangible cultural heritage and intangible cultural heritage projects, and attach importance to legislation, so as to realize the legalization of music culture inheritance. Nowadays, the state has promulgated the "Intangible cultural heritage law", and Liangshan Prefecture has also promulgated the corresponding "Regulations on the protection of intangible cultural heritage in Liangshan Autonomous Prefecture". The government needs to carefully study and further implement these laws and regulations, continuously deepen the understanding of the inheritance law of traditional music, and adhere to the principle of "protection first, rescue first, rational utilization, inheritance and development", and correctly handle the relationship between the protection and utilization of intangible cultural heritage, inheritance and development, culture and tourism. Second, it is necessary to give full play to the effect of disseminators of intangible cultural heritage. The state, local governments and some relevant institutions and organizations can formulate appropriate dynamic management of rewards and punishments for the inheritors, provide security for their livelihood, increase investment in cultural heritage funds, stimulate the participation of the whole people, pay attention to the subjectivity of disseminators of intangible cultural heritage, vigorously support the transmission activities of the inheritors, and stimulate people's cultural confidence of intangible cultural heritage, and protect the production and integrity of intangible cultural heritage. In addition, the government should formulate relevant systems and measures for intangible cultural heritage projects in school education and public cultural venues to create a good social heritage atmosphere. Third, it is required to encourage local folk artists, persons and successors who interest in traditional music to collect and sort out traditional music, so as to promote the inheritance of folk music culture. At the same time, some traditional music competitions will be held regularly to publicize and promote the local intangible music culture. Also, it is better to guide local folk artists and non-governmental organizations to participate in the inheritance of traditional music, promote the protection and development of traditional music by inheritors and the successors, give full play to the subjectivity and initiative of inheritors, and strive for the participation of the whole people in inheritance activities.

\section{Innovative development of inheritance content}

Because the geographical material and cultural ecological environment of Liangshan Prefecture is relatively closed, its music has always retained a relatively simple form and content. The music reflects every aspect of their life, and its text contains a very rich philosophy, moral and ethical concepts, as well as 
the religious beliefs of the whole ethnic group. Whether it is the disseminator or the successor, it is necessary to establish the corresponding cultural self-confidence, carry out in-depth excavation and research of the inherited content, explore the hidden practical context presented by the use and play of the local mother tongue, find its rich, vivid, complete, or incomplete, endangered and damaged heritage content in people's life, and reorganize it. With the interpretation and improvement, unique music thinking, folk style, values, etc. of Liangshan Prefecture can continue. At the same time, it is required to pay attention to the diversification of music inheritance content, sum up the experience of previous inheritance work, and carry out appropriate innovation of traditional music. The author thinks that the most important thing is to make the inheritance, development and innovation. To a certain extent, it can continue the vitality of traditional music in Liangshan Prefecture, and more importantly, open a new contemporary life space for traditional music in Liangshan Prefecture. Innovation is needed to adapt to today's ever-changing social development, whether it is for the inheritor, the successor or the inheritance content and field. Nowadays, the rapid development of the network has caught many people by surprise. In this case, if people still stick to the original way of inheritance, the development of traditional music will suffer heavy damage and resistance. Traditional music culture is something created in the past. People should continue to effectively inherit the traditional culture, turn it into a cultural tradition and a treasure of spiritual civilization of all mankind, and ensure the inheritance and development of intangible cultural heritage.

\section{Conclusion}

Each factor in the inheritance system of intangible traditional music in Liangshan Prefecture is closely related to each other. One link changes, other factors will certainly change accordingly. How to establish a complete and efficient operation system is related to the inheritance and development of contemporary traditional music. From the perspective of intangible cultural heritage, the construction of the entire inheritance system can enable us to better shoulder the dissemination and development of Chinese excellent culture. The word "tradition" not only contains "traditional" text, and it is necessary to explore the text of traditional music through the text. Nowadays, the growth and development of traditional music has changed with time. Therefore, the protection of traditional music in Liangshan Prefecture is not intact protection, but to think about the inheritance, such as what level of things needs to be preserved. And then, it can have a place in the rapid development of the times, and become an open, living cultural system. When talking about Liangshan, people always think of the particularity of its geography and the antiquity and closeness of music. In network era, people in Liangshan Prefecture have used the Internet and mobile phones beyond imagination, and even achieved the phenomenon of "every having Kuaishou App" 3 . Therefore, the geographical closeness and openness of cyberspace have created a special inheritance phenomenon. For the protection and inheritance of traditional music in Liangshan Prefecture, it is necessary to be fully aware of this intertwined and contradictory music inheritance environment. It should not only protect and rescue the music culture and inheritors of the region from the national and government level. And then, these music activities need to rely on the venue and content for inheritance. Otherwise, they will be divorced from the actual situation and cannot spread the essence of folk customs and culture. In a word, the construction of a complete and living music inheritance system is not only to rescue and protect the music text, but also to operate the inheritance mechanism actively and efficiently starting from the particularity of the current era. Only in this way can the vitality of traditional music in Liangshan Prefecture have a continuity to a certain extent, and more importantly, it will open a brand-new contemporary space for traditional music, so as to adapt to the rapid development of contemporary society.

\section{References}

[1] Liao Dan. On the Music of Intangible Cultural Heritage Protection from the Three Characteristics of Traditional Music [J]. Musicology in China, 2013, (01): 50. (in Chinese)

[2] Qiao Jianzhong. "On Traditional Music and Inheritors" [M], Beijing: People's Music Publishing House, 2012: 7. (in Chinese)

[3] Wu Guodong. National Music and Anthropology [M]. Beijing; People's Music Publishing House, 1997. (in Chinese)

[4] Liu Haojia. Analysis of the influence of multicultural music education on the cultural heritage of national music [J]. Time and Space in Music, 2013, 12. (in Chinese)

[5] Li Na. Theoretical and practical research on multicultural music education in ordinary universities [D]. Beijing: Capital Normal University, 2007. (in Chinese)

[6] Tian Qing. Discussions on the Protection of Intangible Cultural Heritage [J]. Literature and Art Studies, 2006, May. (in Chinese)

[7] Huang Xinchu. "The Complete Works of Folk Music of Y Nationality in Sichuan Province", Sichuan Nationalities Publishing House, December 2010. (in Chinese)

[8] Zhu Chongxian. "Classics and Culture of Yi Nationality", Minzu University of China Press, 1994. (in Chinese)

[9] Institute of Ethnic Studies, Chinese Academy of Sciences. "A Brief History of the Yi Nationality", edited and printed by the Investigation Group of Social History of Yunnan Minority, 1963. (in Chinese)

[10] Li Shaoming. "The History of Bashu Nationalities", Sichuan People's Publishing House, 2004. (in Chinese)

\footnotetext{
3 Everyone has Kuaishou App means that the "Kuaishou Video App" is used in Liangshan Prefecture.
} 
[11] Cao Lingshi. "Essays on Music of Yi Nationality", edited and printed by Cultural Bureau of Liangshan Prefecture, 1991. (in Chinese)

[12] Yuan Yan, Jing Zhiming. "An Introduction to the Musical Culture of Ethnic Minorities in Liangshan Prefecture", Sichuan University Press, 2013. (in Chinese)

[13] Zeng Lingshi. "The Relationship Between Yi Folk Songs, Social Life and Customs of Liangshan Prefecture", "Chinese Music", Issue 1, 1992. (in Chinese) 